\title{
Detection and identification of Helicobacter pylori by the polymerase chain reaction
}

\author{
C Clayton, K Kleanthous, S Tabaqchali
}

\begin{abstract}
A polymerase chain reaction for the specific detection of Helicobacter pylori was developed using a primer pair derived from the nucleotide sequence of the urease $A$ gene of $H$ pylori. Specific amplification of a 411 base pair DNA fragment from all strains of $H$ pylori tested was achieved. Ten organisms were detected using the PCR and the technique permitted direct detection of $H$ pylori in clinical biopsy samples. PCR will be useful for both prospective and retrospective investigation of the aetiology and epidemiology of $\boldsymbol{H}$ pylori associated disease.
\end{abstract}

Helicobacter pylori has been implicated in the pathogenesis of active chronic gastritis and peptic ulcer disease in man. ${ }^{1}$ The diagnosis of disease associated with $H$ pylori depends on endoscopic biopsy of the gastric mucosa and detection of $H$ pylori by a urea hydrolysis test, microscopy, and culture. The urease test is a rapid method for detecting $H$ pylori in biopsy specimens, but false positive and false negative results have been reported. ${ }^{2}$ Microscopic analysis of stained biopsy smears is also a non-specific test and has a low sensitivity for

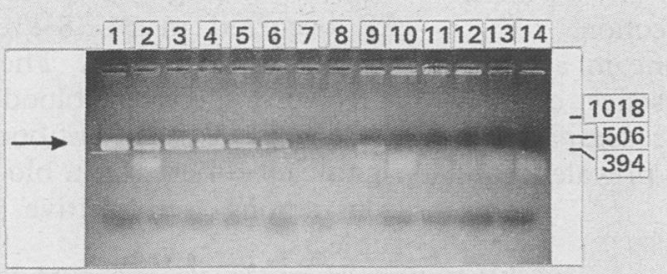

Detection of $H$ pylori by DNA amplification and hybridisation. Ethidium bromidestained agarose gel (top) with the 411 base pair PCR product of $H$ pylori and autoradiograph of the hybridisation (bottom). Lane $1=$ urease clone DNA PTCP3 (1ng), lanes $2-8=10$-fold dilutions of $H$ pylori (630) $10^{6}-1$ cell, lanes $9-14=$ gastric biopsy specimens showing lanes 9 and 13 to be positive for the organism, $1 \mathrm{~Kb}$ ladder molecular weight standard. detecting this organism. Culture of $H$ pylori is time consuming, requiring three to seven days of incubation. A reliable, rapid means of detecting $H$ pylori in tissue samples would therefore be useful. We have cloned the urease genes of $H$ pylori and found them to be conserved and species specific. ${ }^{3}$ The urease genes were sequenced (EMBL accession No $\mathrm{X} 17079)^{4}$ and $H$ pylori specific oligonucleotide primers were synthesised. We report the application of the polymerase chain reaction (PCR) using a pair of these oligonucleotide primers for the detection and identification of H pylori.

A 411 base pair product was amplified from urease gene A (nt 304-715) with the primers 5'-GCCAATGGTAAATTAGTT-3' and 5'CTCCTTAATTGTTTTTAC-3'. The 26 cycle PCR permitted visualisation of the amplified product within five hours (figure). Supernatants of 40 boiled $H$ pylori strains so far examined have given the 411 base pair amplified product on agarose gel electrophoresis. $H$ mustelae and other urease positive bacteria have been found to be PCR negative. The PCR detected as few as $100 \mathrm{H}$ pylori cells, even in mixed cultures (figure). Further use of the PCR on initially amplified samples increased the sensitivity 10 -fold. A similar increase in sensitivity was achieved by Southern hybridisation to an oligonucleotide probe derived from a sequence internal to the amplified product (5'-ATTGACATTGGCGGTAAC-3') (figure).

Initial work has shown that the PCR permits the rapid detection of $H$ pylori directly from gastric biopsy specimens (figure) and this method is currently being further evaluated along with the other diagnostic tests for $H$ pylori infection. This technique can be used to predict quickly relapse of infection after antibacterial treatment of infected patients. We have found that the PCR also detects $H$ pylori in paraffin wax embedded biopsy specimens, allowing retrospective analysis of clinical samples. The PCR should provide a rapid means of detecting non-culturable $H$ pylori and allow the sources and routes of transmission of this important pathogen to be determined.

This work was supported by the Wellcome Trust and Medical Research Council. Some of the above information is included in International Patent Application No PCT/GB 90/01979. 
1 Goodwin CS, Armstrong JA, Marshall BJ. Campylobacter pyloridis, gastritis, and peptic ulceration. J Clin Patho 1986;39:353-65.

2 Hazell SL, Borody TJ, Gal A, Lee A. Campylobacter pyloridis. I. Detection of urease as a marker of bacteria colonisation and gastritis. Am J Gastroenterol 1987;82:292-96.

3 Clayton CL, Wren BW, Mullany P, Topping A, Tabaqchali
S. Molecular cloning and expression of Campylobacter pylori species-specific antigens in Escherichia coli $\mathrm{K}-12$. Infect Immun 1989;57:623-9.

4 Clayton CL, Pallen MJ, Kleanthous H, Wren BW, Tabaqchali $S$. Nucleotide sequence of two genes from Helicobacter pylori encoding for urease subunits. Nucleic Acids Res 1990;18:362.

\title{
Helicobacter pylori and $\mathrm{ABO}$ blood groups
}

\author{
R J L F Loffeld, E Stobberingh
}

\begin{abstract}
A serological study was carried out to assess the prevalence of antibodies to Helicobacter pylori and compare it with the distribution of ABO blood groups. Serum samples from 402 healthy blood donors were tested with an IgG enzyme linked immunosorbent assay. There was no difference in blood groups between those who were seropositive and those who were seronegative, which suggests that blood group $O$ is not a risk factor for acquiring $\boldsymbol{H}$ pylori infection.
\end{abstract}

Helicobacter pylori has been implicated as the major cause of type B (antral) gastritis. The bacterium also has an important role in the pathogenesis of duodenal ulcer disease. ${ }^{1-3}$ Blood group $\mathrm{O}$ has been regarded as a risk factor for duodenal ulcers for many years, ${ }^{4}$ although the reasons for this are not clear.

Because duodenal ulcer disease is associated with antral $H$ pylori infection in $90-100 \%$ of the cases, blood group $\mathrm{O}$ might also be a risk factor for acquiring $H$ pylori infection.

A prospective study was done in a group of healthy subjects. The presence of IgG antibodies against $H$ pylori was compared in ABO blood groups with the prevalence of Rhesus factor.

\section{Methods}

The group comprised 402 healthy blood donors (363 men and 39 women, mean age 42 years, range 19-65 years). ABO blood group

\begin{tabular}{lrrlll}
\hline & \multicolumn{2}{c}{ Blood group } & & \\
\cline { 2 - 5 } & $O$ & $A$ & $B$ & $A B$ & Total numbers \\
\hline Seropositive & $56(39 \%)$ & $70(49 \%)$ & $13(9 \%)$ & $4(3 \%)$ & 143 \\
Seronegative & $120(46 \%)$ & $109(42 \%)$ & $21(8 \%)$ & $9(4 \%)$ & 259 \\
\hline
\end{tabular}

and rhesus factor were determined with standard serological tests (Centraal laboratorium van de Bloedtransfusiedienst, CLB, Amsterdam, The Netherlands). Sera were taken for the assessment of IgG antibodies against $H$ pylori with an enzyme linked immunosorbent assay (ELISA), using a crude sonicate of five different strains of $H$ pylori as antigen. This assay has sensitivity and specificity values of $98 \%$ and $94 \%$, respectively. This method has been described previously. ${ }^{5}$

Statistical analysis was done with the $\chi^{2}$ test.

\section{Results}

One hundred and forty three $(35.5 \%)$ subjects had antibodies against $H$ pylori, the remainder (259 or $64.5 \%$ ) were seronegative. Of those seropositive, $112(78.3 \%)$ were rhesus D positive compared with $219(84.5 \%)$ of those who were seronegative. This difference was not significant.

One hundred and seventy six $(43.8 \%)$ blood donors were of blood group O; $179(44.5 \%)$ were of blood group A. Blood groups B and $A B$ occurred in $34(8.4 \%)$ and $13(3.3 \%)$ subjects, respectively. The table shows the correlation between blood groups and the presence of $H$ pylori antibodies. There was no significant difference in blood group distribution among seropositive and seronegative subjects.

\section{Discussion}

In a recent report no association was found between blood group, antibody prevalence, and $H$ pylor infection. ${ }^{6}$ In this study $H$ pylori was detected using a rapid urease method for gastric biopsy specimens. This could be a possible drawback, because an unknown number of patients could have cleared or eradicated $H$ pylori as a result of concomitant treatment with antibiotics or bismuth preparations. Serological studies for 